\title{
Phytoglycogen Nanoparticle Delivery System for Inorganic Selenium Reduces Cytotoxicity without Impairing Selenium Bioavailability
}

This article was published in the following Dove Press journal: International Journal of Nanomedicine

\author{
Tamiru N Alkie' \\ Jondavid de Jong ${ }^{1,2}$ \\ Emily Moore ${ }^{2}$ \\ Stephanie J DeWitte-Orr (D) \\ 'Department of Health Sciences, Wilfrid \\ Laurier University, Waterloo, ON N2L \\ $3 \mathrm{C5}$, Canada; ${ }^{2}$ Glysantis Inc, Guelph, ON \\ NIC OAI, Canada
}

Correspondence: Stephanie J DeWitte-Orr Department of Health Sciences, Wilfrid Laurier University, Waterloo, ON N2L 3C5, Canada

$\mathrm{Tel}+\mid 5198840710$

Email sdewitteorr@wlu.ca
Purpose: Selenium is an essential trace element that supports animal health through the antioxidant defense system by protecting cells from oxidative-related damage. Using inorganic selenium species, such as sodium selenite ( $\mathrm{Na} \mathrm{Sel}$ ), as a food supplement is costeffective; however, its limitation as a nutritional supplement is its cytotoxicity. One strategy to mitigate this problem is by delivering inorganic selenium using a nanoparticle delivery system (SeNP).

Methods: Rainbow trout intestinal epithelial cells, bovine turbinate cells and bovine intestinal myofibroblasts were treated with soluble Na Sel or SeNPs. Two SeNP formulations were tested; SeNP-Ionic where inorganic selenium was ionically bound to cationic phytoglycogen (PhG) NPs, and SeNP-Covalent, where inorganic selenium was covalently bound to PhG NPs. Selenium-induced cytotoxicity along with selenium bioavailability were measured.

Results: SeNPs (SeNP-Ionic or SeNP-Covalent) substantially reduced cytotoxicity in all cell types examined compared to similar doses of soluble inorganic selenium. The SeNP formulations did not affect selenium bioavailability, as selenium-induced glutathione peroxidase (GPx) activity and GPx1 transcript levels were similarly elevated whether cells were treated with soluble Na Sel or SeNPs. This was the case for all three cell types tested.

Conclusion: Nanoparticle-assisted inorganic selenium delivery, which demonstrated equal bioavailability without causing deleterious cytotoxic side effects, has potential applications for safely supplementing animal diets with inorganic selenium at what are usually toxic doses.

Keywords: cytotoxicity, bovine, GPx, phytoglycogen, rainbow trout, sodium selenite

\section{Introduction}

Selenium is an essential micronutrient forming the active catalytic site of several selenium-dependent antioxidant enzymes such as glutathione peroxidases (GPx). GPx catalyzes the reduction of hydroperoxides and hydrogen peroxide by reduced glutathione to protect cells from oxidative damage. ${ }^{1,2}$ When consumed at high doses, selenium initiates the induction of reactive oxygen species causing oxidative stress in cells which results in cytotoxicity. ${ }^{3}$ Toxicity of selenium for humans and animals not only depends on the quantity of the element consumed but also its chemical form. ${ }^{4-6}$ However, all forms of selenium species have a very narrow range of nutritional and tolerable upper intake levels. ${ }^{7}$ Selenium at supranutritional doses has therapeutic value for treating several human health conditions including some cancers. ${ }^{8-10}$ Conversely, when selenium levels drop below the recommended dose, 
selenium deficiency causes multiple organ pathologies. ${ }^{7,11}$ Mostly, supplemental selenium is acquired through diet, ${ }^{12}$ and supplementing the diet of animals with sodium selenite ( $\mathrm{Na} \mathrm{Sel}$ ) and selenium yeast is common due to the variation of selenium content between feed ingredients. ${ }^{8,12}$

Selenium can be delivered either 1) in its compound state, 2) self-assembled into nanoparticles with the help of proteins or reducing agents (nano-selenium), or (3) conjugated onto the surface of nanoparticles. ${ }^{13-16} \mathrm{Na}$ Sel is an inorganic form of selenium that can be used as a supplement, and although it is commonly used as a nutritional supplement over organic selenium species due to its low cost, its cytotoxic effects are well established. ${ }^{17}$ Nanoselenium, such as zerovalent selenium nanoparticles and selenium polysaccharides, are selenium supplements that can be consumed with lower risk of toxicity and higher levels of bioavailability. ${ }^{18,19}$ In animals including fish, dietary nano-selenium has been shown to improve the growth performance and antioxidant defense system as it is a more readily available source of selenium. ${ }^{16,20-23}$ One of the limitations of nano-selenium is its synthesis requiring proteins such as albumin as reducing agents, which increases cost and size variability with nano-selenium synthesized in bacteria. ${ }^{24}$ Finally, nanoparticles that have been used to deliver drugs can also be used to deliver micronutrients, including inorganic selenium, that otherwise are toxic. To this end, inorganic selenium encapsulated into chitosan nanoparticles have demonstrated lower cytotoxic effects, while maintaining selenium's antioxidant properties. ${ }^{25,26}$ In the present study, phytoglycogen nanoparticles (PhG NPs), a naturally occurring nanoparticle derived from sweet corn (commercialized as NanoDendrix $^{\mathrm{TM}}$ by Glysantis ${ }^{\mathrm{TM}}$, Guelph, ON, Canada) was used to deliver inorganic selenium (either sodium selenite ( $\mathrm{Na} \mathrm{Sel}$ ) or selenium dioxide) using two forms of chemistry, namely, ionic and covalent bonding. ${ }^{27}$ Notably, the hydrodynamic diameter of the selenium-conjugated nanoparticles (SeNPs), 53-68 nm, is comparable to most nano-selenium produced by chemical technology. ${ }^{24} \mathrm{PhG}$ NPs are superior to polysaccharides such as chitosan because chitosan is synthesized mostly from chitin shells of shrimp and other crustaceans and their solubility in water and absolute purity are common concerns. Additionally, chitosan requires extensive chemical modifications to obtain high-grade chitosan derivatives. $^{28} \mathrm{PhG}$ NPs are highly water soluble with high purity and are monodisperse in aqueous solutions. The dendrimeric glucose structure of PhG NPs makes these NPs amenable to chemical and enzymatic modifications for incorporating various structural and functional groups to which a range of therapeutic molecules can be bound. ${ }^{27}$ Additionally, PhG NPs can be degraded into Dglucose by intracellular enzymes and further metabolized by normal physiological glycolysis as energy sources to the cells. ${ }^{27}$ PhG NPs have been used in a previous study for efficient delivery of RNA molecules into fish cells. ${ }^{29}$ The present study tested whether this biodegradable nanoparticle delivery method for inorganic selenium reduced selenium-mediated cytotoxicity without impairing bioavailability, thus allowing a higher tolerable intake level of selenium; a desirable feature when supplementing diets. Thus, the effects of SeNPs (SeNP-Ionic or SeNPCovalent) were evaluated in intestinal cells of economically important farmed animals like rainbow trout and in cells derived from bovine species. In the current study, SeNPs possessed reduced cytotoxicity, but maintained selenium's bioavailability as shown by increased upregulation of the expression of GPx1 and the activity of GPx.

\section{Materials and Methods Cells}

RTgutGC, an epithelial cell line derived from the rainbow trout (Oncorhynchus mykiss) gut, was obtained from Dr. Niels Bols (University of Waterloo, ON). ${ }^{30}$ RTgutGC was cultured in Leibovitz's L-15 medium (Hyclone) supplemented with $1 \%$ penicillin/streptomycin and $10 \%$ fetal bovine serum (FBS) (Seradigm Life Science). Cells were grown in $75 \mathrm{~cm}^{2}$ plastic tissue culture flasks (BD Falcon, Bedford, MA) and sub-cultured every 10 days. BTC, a cell line derived from the turbinate of Bos taurus, was obtained from the American Type Culture Collection $\left(\right.$ ATCC $^{\circledR}$ CRL- $1390^{\mathrm{TM}}$ ). The bovine intestinal myofibroblast cell line (BT-IMF) was derived from the small intestine of a Bos taurus fetal calf delivered through cesarean section and was obtained from Dr. Lucy Lee (University of the Fraser Valley, BC). Both bovine cell lines were propagated in Dulbecco's Modified Eagle's Medium (DMEM) (Corning) supplemented with 1\% penicillin/streptomycin, $10 \%$ heat inactivated FBS, $1 \%$ nonessential amino acids and $25 \mathrm{mM}$ HEPES and subcultured every 7 days in $25 \mathrm{~cm}^{2}$ Falcon tissue culture flasks. Unless otherwise indicated, in all experiments, fish cells were incubated at $20^{\circ} \mathrm{C}$ in the absence of $\mathrm{CO}_{2}$, whereas bovine cells were incubated at $37^{\circ} \mathrm{C}$ in a $5 \% \mathrm{CO}_{2}$ humidified incubator. 


\section{Preparation of Phytoglycogen NPs (PhG NPs) and Inorganic Selenium Derivatives}

Cationic PhG NPs prepared as previously described were used to bind inorganic selenium derivatives. ${ }^{29}$ To form SeNP-Ionic, $2.5 \mathrm{~g} \mathrm{Na} \mathrm{Sel}\left(\mathrm{Na}_{2} \mathrm{SeO}_{3}\right.$; Sigma Aldrich) and $2.5 \mathrm{~g}$ cationic PhG NPs were mixed in $50 \mathrm{~mL}$ deionized water, stirred overnight, dialyzed, and lyophilized. To form SeNP-Covalent, $15 \mathrm{mg} \mathrm{LiCl}$ and $1.5 \mathrm{~mL} \mathrm{~N}$,N-dimethylacetamide (DMAc) were added to $84.3 \mathrm{mg}$ PhG NPs in a conical Wheaton vial equipped with a triangular stir bar. The white suspension was then heated to $80^{\circ} \mathrm{C}$ for $2 \mathrm{hr}$ with stirring. To the opaque reaction mixture, $55 \mathrm{mg}$ selenium dioxide (Sigma Aldrich) was added, which was cooled and left to stir overnight. Following the addition of $33 \mathrm{mg}$ $\mathrm{K}_{2} \mathrm{CO}_{3}$ and stirring for an hour, the crude product was washed with $10 \mathrm{~mL}$ distilled $\mathrm{Et}_{2} \mathrm{O}$ and centrifuged (for a total of four times) to recover a pellet which was dried under vacuum at $45-50^{\circ} \mathrm{C}$. The synthesis of the two selenium formulations is illustrated in Figure 1. In both SeNP-Ionic and SeNP-Covalent modifications, the amount of selenium incorporated into the PhG NPs was determined by hydrolyzing PhG NPs with 70\% nitric acid and quantifying by an UV-vis colorimetric assay using standard curves generated from known concentrations of Na Sel as described previously. ${ }^{31}$ The prepared SeNP (SeNP-Ionic or SeNP-Covalent) were further characterized for particle size using previously described methods. ${ }^{29}$

\section{Cytotoxicity of SeNPs in Fish and Bovine Cells}

The effects of soluble inorganic selenium alone and SeNPs (SeNP-Ionic or SeNP-Covalent) on cell metabolism and cell membrane integrity was evaluated using either RTgutGC that was seeded at $3 \times 10^{4}$ cells/well in a 96well plate (BD Falcon) for $24 \mathrm{hr}$ in L-15 medium and incubated at $20^{\circ} \mathrm{C}$ or BTC and BT-IMF which were seeded at $1 \times 10^{4}$ cells/well in a 96 well-plate in DMEM for $24 \mathrm{hr}$ and incubated at $37^{\circ} \mathrm{C}$. The cell monolayer was then washed twice with media and treated with a 10 -fold serial dilution of soluble $\mathrm{Na}$ Sel, SeNP-Ionic and SeNPCovalent. Na Sel was used as the inorganic selenium control in all experiments. Bovine cells were treated with $\mathrm{Na}$ Sel or SeNPs ranging from 10 to $0.0001 \mu \mathrm{M}$ while rainbow trout cells exhibited greater resistance to selenium-induced cytotoxicity and were treated with a range of $\mathrm{Na}$ Sel or SeNPs between 100 and $0.001 \mu \mathrm{M}$. The selenium concentration in the SeNP preparations was calculated based on the amount of selenium incorporated into the cationic PhG NPs as described above and matched with the concentration of the soluble Na Sel. Control groups received media alone (Media) or cationic $\mathrm{PhG}$ NPs without selenium (Mock NPs). After 24, 48, 72 and $96 \mathrm{hr}$ of treatment, medium was removed, the cell monolayer was washed twice with 1x PBS and incubated with AlamarBlue $(\mathrm{AB})$ and 5-carboxyfluorescein diacetate-acetoxymethyl ester (CFDA-AM) (Invitrogen) for $1 \mathrm{hr}$ at $37^{\circ} \mathrm{C}$ for bovine cells and at $20^{\circ} \mathrm{C}$ for fish cells. Fluorescence was measured in a Synergy HT plate reader (BioTek,

Ionic:
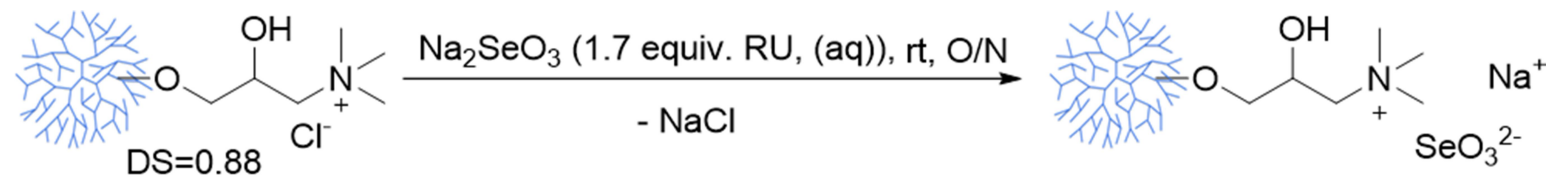

Covalent:
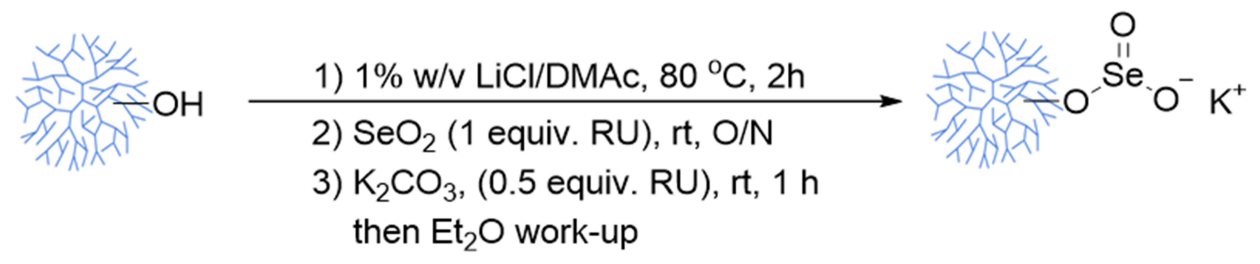

equiv. $\mathrm{RU}=$ molar equivalent of repeating unit

Figure I Illustration of the synthesis of the two selenium formulations. $\mathrm{Na}_{2} \mathrm{SeO}_{3}$ was bound by electrostatic interaction to PhG NPs (ionic formulation). In the second formulation branched PhG NPs was linked with selenium dioxide (covalent formulation). The synthesized products were lyophilized or dried under vacuum. rt refers to room temperature. N,N-dimethylacetamide (DMAc). All other abbreviations are given in the materials and methods section. 
Winooski, VT) at the excitation/emission wavelengths of $530 / 590 \mathrm{~nm}$ and $485 / 528 \mathrm{~nm}$ for $\mathrm{AB}$ and CFDA-AM, respectively. All experiments were performed in three independent trials.

\section{Determining the Expression of GPxI}

RTgutGC, BTC and BT-IMF cultured in the same conditions as described above were treated with $0.01 \mu \mathrm{M}$ Na Sel or SeNPs (SeNP-Ionic or SeNP-Covalent) for $48 \mathrm{hr}$. The $0.01 \mu \mathrm{M}$ dose was chosen as it was non-toxic dose for all three cell lines. Control groups were media alone and cationic PhG-NP alone (Mock NPs). Total RNA was extracted from the cells using TRIzol ${ }^{\circledR}$ Reagent (Invitrogen). The $2.5 \mu \mathrm{g}$ of RNA was treated with DNAse (DNA Free ${ }^{\circledR}$, Ambion, Austin, TX) following manufacturer's instructions and cDNA was synthesized from 500 ng of RNA using iScript ${ }^{\mathrm{TM}}$ cDNA Synthesis Kit System (Bio-Rad). The expression of GPx1, a ubiquitously expressed selenium specific form of GPx in fish and bovine cells, was quantified by SYBR Green real-time PCR (BioRad). The primer pairs for bovine $\beta$ actin (AY141970) were 5'-GCCCATCTATGAGGGGTACG-3' and 5'-ATGTCACG GACGATTTCCGC-3', and for bovine GPx1 (BC149308) were 5-TTGGGCATCAGGAAAACGCC-3' and 5'-GCCA TTCACCTCGCACTTTTC-3'. Rainbow trout $\beta$ actin (NM_001124235) was amplified by the primer pairs 5'GTCACCAACTGGGACGACAT-3' and 5'-GTACATGGC AGGGGTGTTGA-3', and GPx1 (HE687023) by 5'-AGTT CGGACATCAGGAGAACTG-3' and 5'-TCAAGGAGCT GGAACTTAGGC-3'. The PCR reactions included: $4 \mu \mathrm{L}$ of diluted cDNA (1:10), 2x SsoFast EvaGreen Supermix (Bio-Rad), $0.2 \mu \mathrm{m}$ forward, $0.2 \mu \mathrm{M}$ reverse primer and nuclease-free water in a total volume of $10 \mu \mathrm{L}$. The qPCR conditions for all genes were $98^{\circ} \mathrm{C}$ for $2 \mathrm{~min}, 40$ cycles of $98^{\circ} \mathrm{C}$ for $5 \mathrm{sec}, 55^{\circ} \mathrm{C}$ for $10 \mathrm{sec}$ and $95^{\circ} \mathrm{C}$ for $10 \mathrm{sec} . \mathrm{A}$ melting curve was completed from $65^{\circ} \mathrm{C}$ to $95^{\circ} \mathrm{C}$ with a read every $5 \mathrm{sec}$. Gene expression levels were normalized to $\beta$-actin and expressed as relative fold changes compared to media treated group.

The primer pairs were designed using NCBI Primer blast.

\section{Determining GPx Activity}

As a measure of selenium bioavailability, glutathione peroxidase (GPx) activity was determined from cell culture homogenates. For this purpose, RTgutGC was seeded at $1 \times 10^{6}$ cells/well in a 6 -well plate (BD Falcon) and incubated for $24 \mathrm{hr}$ at $20^{\circ} \mathrm{C}$ in RTgutGC culture medium. BTC and BT-IMF were seeded at $4 \times 10^{5}$ cells/well in a 6 -well plate in BT culture medium for $24 \mathrm{hr}$ at $37^{\circ} \mathrm{C}$ in a $5 \% \mathrm{CO}_{2}$ humidified incubator. The cell monolayer was washed twice with media and cells were treated with $0.01 \mu \mathrm{M}$ $\mathrm{Na}$ Sel or SeNPs (SeNP-Ionic or SeNP-Covalent), which was the non-toxic concentration for all cell types and incubated for $72 \mathrm{hr}$. Control groups include media alone and cationic PhG NP alone (Mock NPs). Cells were washed twice with cold 1x PBS, scraped, collected and ultra-sonicated in a lysis buffer $(50 \mathrm{mM}$ Tris- $\mathrm{HCl}, \mathrm{pH} 7.5$, $5 \mathrm{mM}$ EDTA and $1 \mathrm{mM}$ DTT) for $30 \mathrm{sec}$. Cell homogenates were centrifuged at $15,000 \times \mathrm{g}$ for $20 \mathrm{~min}$ at $4{ }^{\circ} \mathrm{C}$, supernatant collected, and total protein concentration in the supernatant was determined by Quick Start ${ }^{\mathrm{TM}}$ Bradford Protein Assay (Bio-Rad). GPx activity in the cell supernatant was determined using the Glutathione Peroxidase Assay Kit (Cayman Chemical, MI, USA). GPx activity was expressed as $\mathrm{nmol} / \mathrm{min} / \mathrm{mL}$. Data were normalized to total protein concentrations of the cell lysates. All experiments were performed in three independent trials.

\section{Statistics}

Data were analyzed in GraphPad Prism (Version 7, GraphPad, La Jolla, CA). Results obtained from GPx assays and GPx1 expression were analyzed by one-way analysis of variance with a Dunnett's test. Seleniuminduced cytotoxicity generated from cell culture studies were analyzed with a Kruskal-Wallis (nonparametric) test. In all cases, comparisons were made between treatment groups (Media, Mock NPs, Na Sel, SeNP-Ionic and SeNP-Covalent) within a defined concentration for each time point. Results were given as mean values and standard errors. A value of $\mathrm{P}<0.05$ was considered significant.

\section{Results}

\section{SeNPs Characterization}

SeNPs (SeNP-Ionic or SeNP-Covalent) were first characterized for their hydrodynamic sizes. SeNP-Covalent and SeNP-Ionic had a diameter of about $68.54 \mathrm{~nm}$ and 55.02 $\mathrm{nm}$, respectively, which is larger than the original cationic PhG NPs (53.56 nm; Figure 2). The particles had a very low polydispersity index, ranging from 0.066 to 0.107 , indicating a monodisperse solution. The amount of selenium incorporated into PhG NPs varied between the methods of modification. In the case of SeNP-Covalent, selenium was incorporated at $180 \mu \mathrm{g}$ selenium/mg $\mathrm{PhG}$ NPs, whereas for SeNP-Ionic, it was $125 \mu \mathrm{g} / \mathrm{mg}$ PhG NPs. 
A

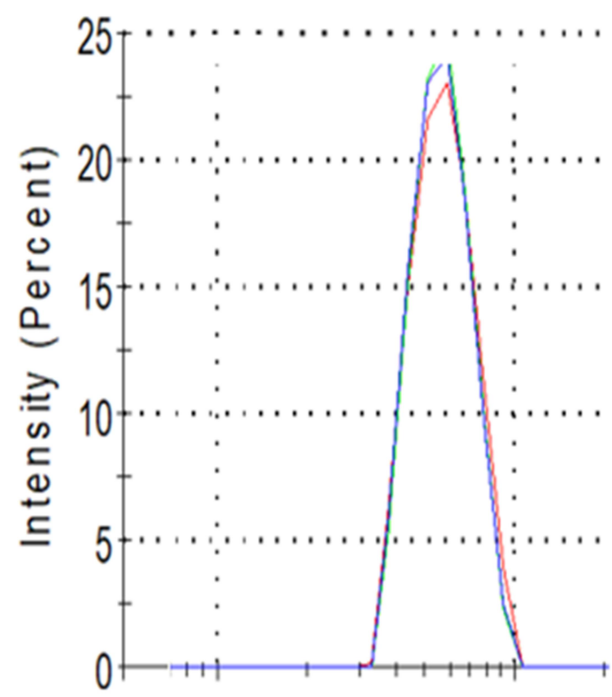

10

100
B

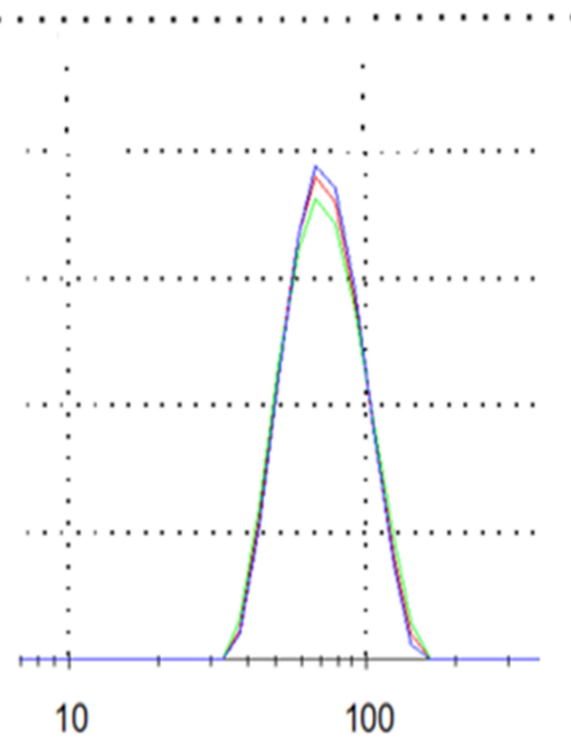

\section{Size (d.nm)}

C

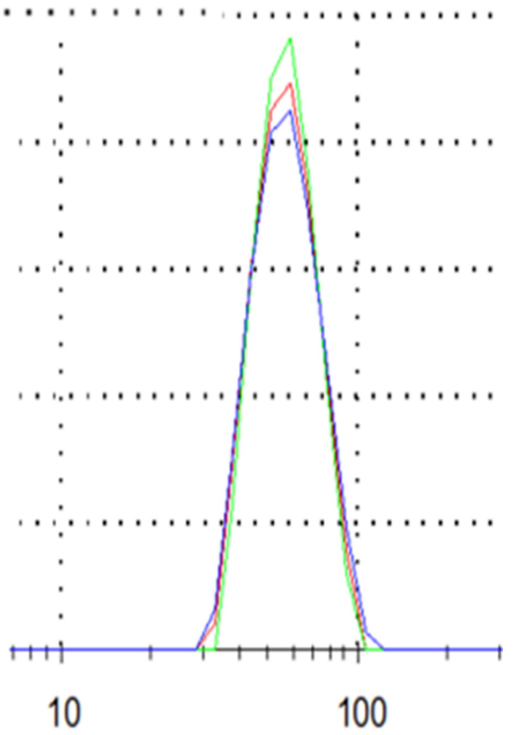

10

100

Figure 2 Physical properties of SeNPs. (A) Cationic PhG NPs (Mock NPs), (B) SeNP-Covalent and (C) SeNP-lonic. The size of SeNP was measured at room temperature at a concentration of $10 \mu \mathrm{g} / \mathrm{mL}$.

\section{SeNPs Have Reduced Cytotoxicity in Fish Cells}

Next, the cytotoxic effects of soluble inorganic selenium or SeNPs in the fish intestinal epithelial cell line, RTgutGC was examined. $\mathrm{Na}$ Sel and SeNPs both exhibited dose-dependent cytotoxicity as indicated using AlamarBlue (Figure 3A) and CFDA-AM (Figure 3B) assays. Indeed, Na Sel was extremely toxic to fish intestinal cells at concentrations ranging from 1 to $100 \mu \mathrm{M}$ at 24, 48, 72 and $96 \mathrm{hr}$ post-treatment. At a higher dose $(10$ and $100 \mu \mathrm{M}), \mathrm{Na}$ Sel induced significant
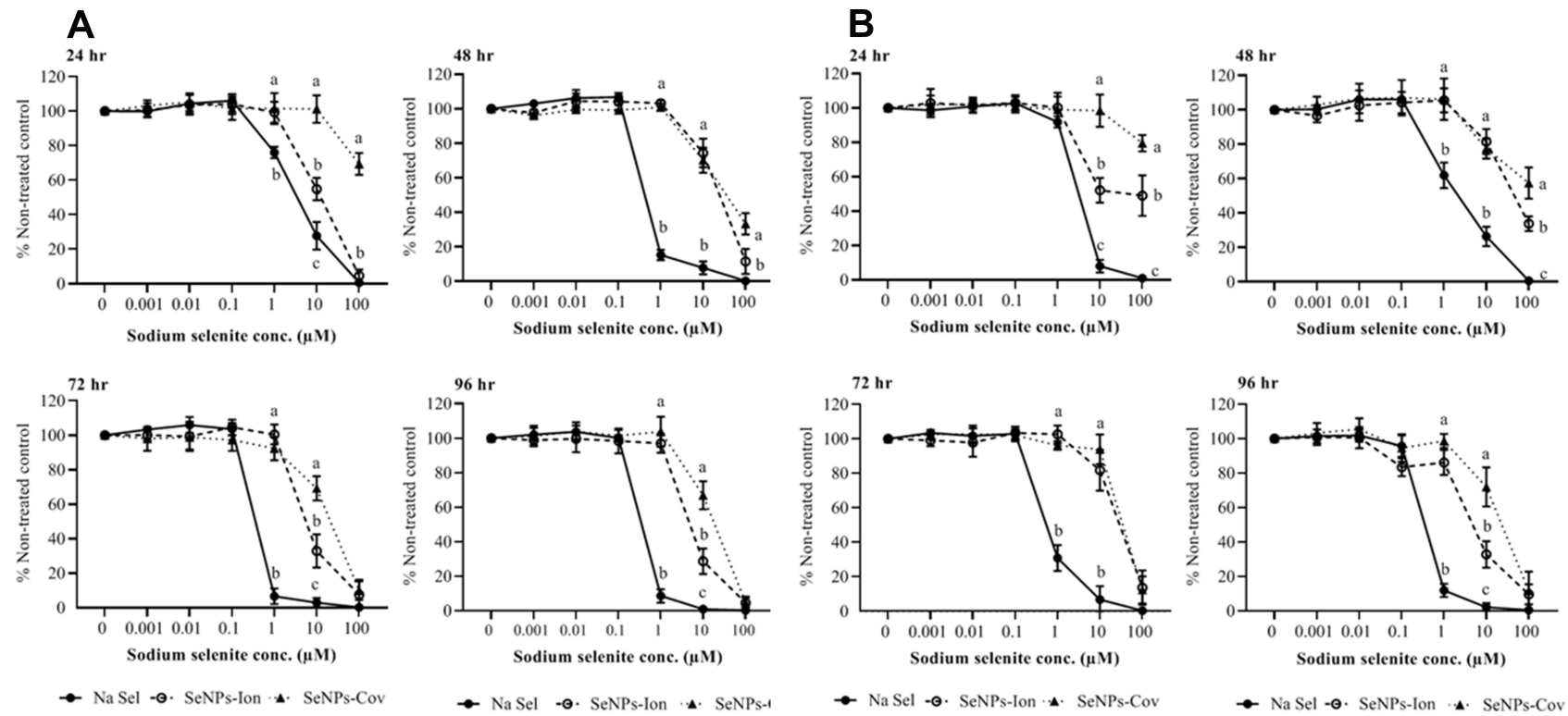

Figure 3 Evaluation of the toxicity of Na Sel and SeNPs (SeNP-lonic or SeNP-Covalent) in rainbow trout intestinal cells (RTgutGC). (A) AlamarBlue and (B) CFDA-AM assays. RTgutGC cells were treated with serially diluted Na Sel, SeNP-lonic (SeNPs-lon) or SeNP-Covalent (SeNPs-Cov) for $24,48,72$ and 96 hr and cellular toxicity was measured. Data are represented as mean \pm SEM. Significance $(P<0.05)$ was tested between $\mathrm{Na}$ Sel and SeNP groups within a defined dose for each time point. Different letters within a defined dose show significant differences. 
cytotoxicity as early as $24 \mathrm{hr}$ post-treatment; while $1 \mu \mathrm{M} \mathrm{Na}$ Sel also induced significant toxicity but at later time points. Cytotoxicity was substantially reduced in SeNPs. In both assays, $1 \mu \mathrm{M}$ SeNP-Ionic and SeNP-Covalent did not induce substantial toxicity at all time points investigated. Even at 10 $\mu \mathrm{M}$, SeNP-Covalent demonstrated reduced toxicity compared to the other forms. At the lower concentration ranges $(0.001-0.1 \mu \mathrm{M})$, no cytotoxicity was detected for all formulations at all time points. Concentration-matched cationic $\mathrm{PhG}$ NPs that delivered the highest concentrations of $\mathrm{Na}$ Sel, which were 100 and $10 \mu \mathrm{M}$ induced about 23\% and 3$7 \%$ cytotoxicity, respectively, in fish intestinal epithelial cells. All other concentrations of our cationic PhG NPs did not cause any cytotoxicity (data not shown).

The lethal concentration $50\left(\mathrm{LC}_{50}\right)$ of the three formulations was calculated for RTgutGC at $24 \mathrm{hr}$ using the AlamarBlue (AB) data (Table 1). Data obtained from CFDA-AM were similar to that of $\mathrm{AB}$ (Figure 3B).

\section{SeNPs Have Reduced Cytotoxicity in Bovine Cells}

The effects of SeNPs (SeNP-Ionic or SeNP-Covalent) and inorganic selenium alone on cytotoxicity were measured next in bovine cell lines (Figures 4 and 5). Na Sel and SeNPs produced striking differences in cellular
Table I Cytotoxicity Index of $\mathrm{Na}$ Sel and SeNPs in Fish and Bovine Cells (Mean LC L0 \pm SEM; $\mu \mathrm{m}$ )

\begin{tabular}{|l|l|l|l|}
\hline Cell line & Na Sel & SeNP-lonic & SeNP-Covalent \\
\hline RTgutGC & $0.96 \pm 0.11$ & $9.10 \pm 0.49$ & $18.45 \pm 3.79$ \\
BTC & $0.07 \pm 0.01$ & $4.52 \pm 0.75$ & $4.16 \pm 1.26$ \\
BT-IMF & $0.07 \pm 0.02$ & $1.88 \pm 0.43$ & $6.19 \pm 1.01$ \\
\hline
\end{tabular}

toxicity. In both bovine-origin cells, SeNPs effectively reduced induced toxicity by several fold compared to $\mathrm{Na}$ Sel alone. Bovine turbinate cells (BTC) were susceptible to the free form of $\mathrm{Na}$ Sel toxicity, with cytotoxicity beginning at $0.1 \mu \mathrm{M}$. At later time points, $0.1,1$ and 10 $\mu \mathrm{M}$ Na Sel were highly toxic to BTC as determined by both complementary assays (Figure 4A and B). Conversely, the toxicity was substantially reduced in SeNPs groups. In both assays (AlamarBlue and CFDAAM), even $1 \mu \mathrm{M}$ SeNP-Ionic and SeNP-Covalent lacked cytotoxic effects at all time points tested. At $10 \mu \mathrm{M}$, however, SeNPs formulations were toxic. In BTC, ionic and covalent forms exhibited almost identical cytotoxicity profiles. No formulation exhibited substantial toxicity at lower concentrations $(0.01-0.0001 \mu \mathrm{M})$ for all time points. In BTC, concentration matched cationic $\mathrm{PhG}$ NPs used to deliver the highest concentration of $\mathrm{Na}$ Sel, which was $10 \mu \mathrm{M}$, induced 5-9\% cytotoxicity, whereas all other concentrations of cationic PhG NPs did
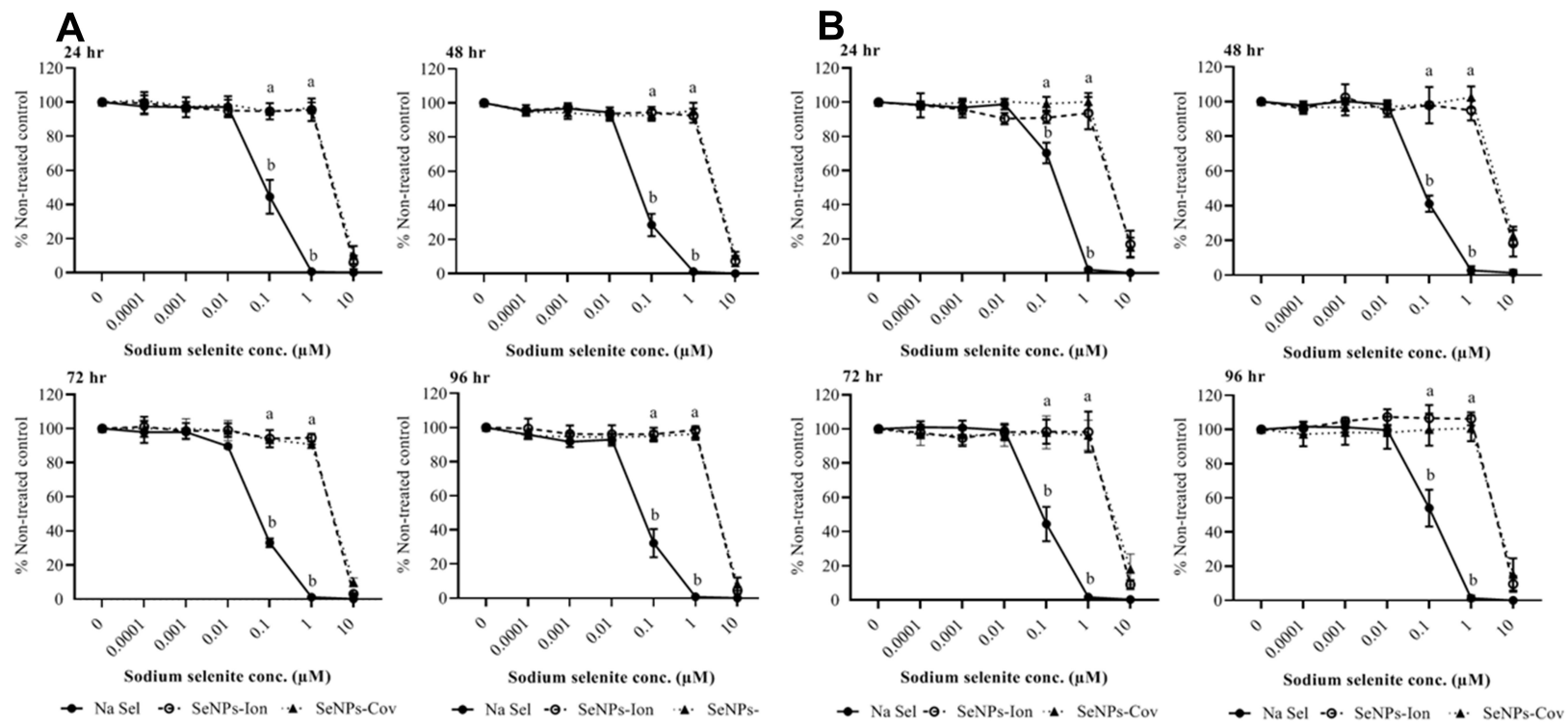

Figure 4 Effects of Na Sel and SeNPs (SeNP-lonic or SeNP-Covalent) on cell viability in bovine turbinate cells (BTC). (A) AlamarBlue and (B) CFDA-AM assays. BTC cells were treated with $\mathrm{Na}$ Sel, SeNP-lonic (SeNPs-lon) and SeNP-Covalent (SeNPs-Cov) at doses ranging from 10 and $0.0001 \mu M$. Data are expressed as mean \pm SEM. Significance $(P<0.05)$ was tested between $\mathrm{Na}$ Sel and SeNP treatment groups within a defined dose for each time point. Different letters within a defined dose show significant differences between groups. 

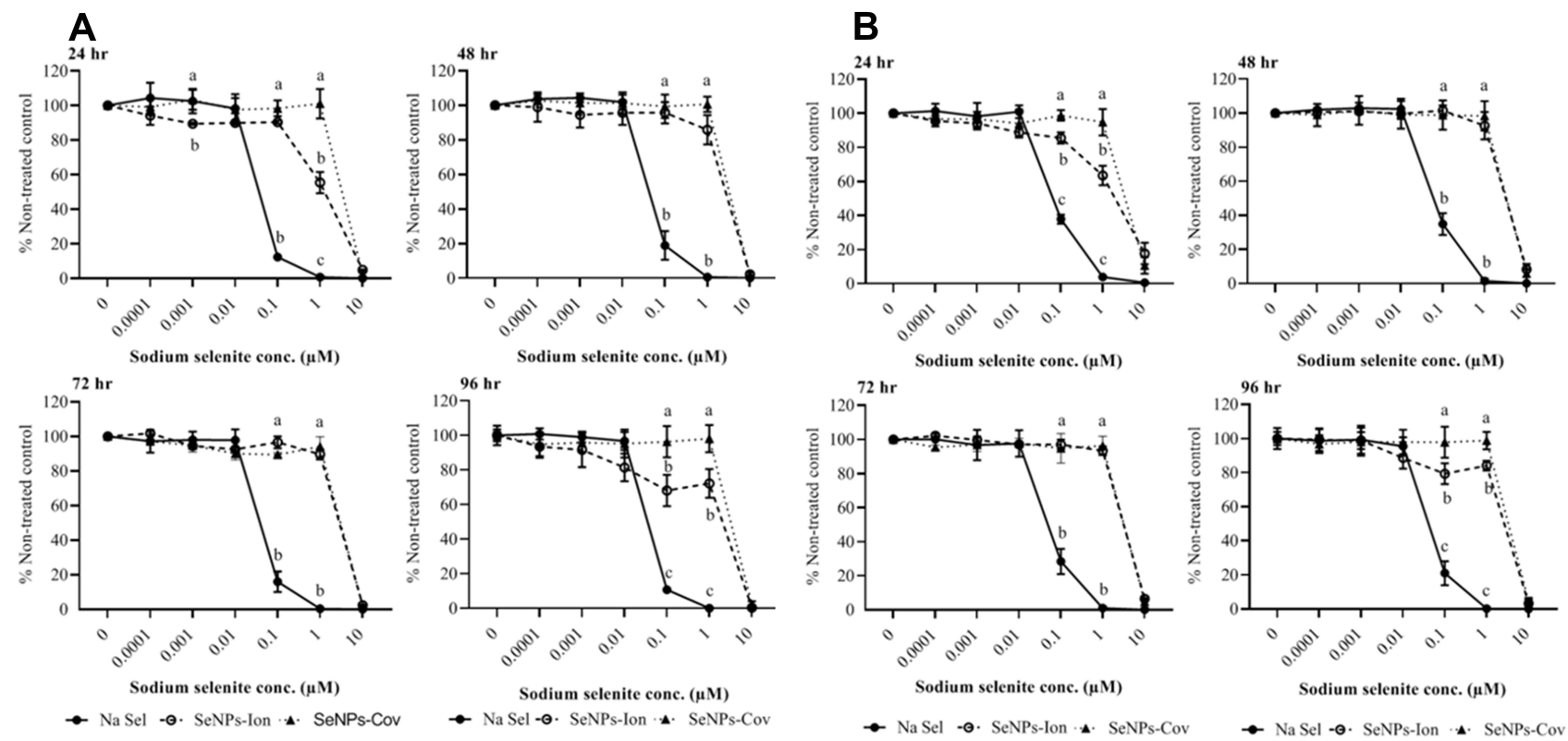

Figure 5 Effects of $\mathrm{Na}$ Sel and SeNPs (SeNP-lonic or SeNP-Covalent) on cell viability in bovine intestine myofibroblast cells (BT-IMF). (A) AlamarBlue and (B) CFDA-AM assays. BT-IMF cells were treated with Na Sel, SeNP-lonic (SeNPs-lon) and SeNP-Covalent (SeNPs-Cov) at doses ranging from 10 and $0.000 \mathrm{I} \mu$ M. Data are expressed as mean \pm SEM. Significance $(P<0.05)$ was tested between $\mathrm{Na}$ Sel and SeNP treatment groups within a defined dose for each time point. Different letters within a defined dose show significant differences between groups.

not cause cytotoxicity. In $\mathrm{BTC}$, the $\mathrm{LC}_{50}$ for $\mathrm{Na} \mathrm{Sel}$, SeNP-Ionic and SeNP-Covalent were calculated as indicated in Table 1.

The effects of $\mathrm{Na}$ Sel and SeNPs toxicity in bovine intestine myofibroblast cells (BT-IMF) (Figure 5A and B) resembled that in BTC. BT-IMF was highly susceptible to $\mathrm{Na}$ Sel at concentrations ranging from 0.1 to 10 $\mu \mathrm{M}$. The ionic and covalent SeNP forms had very similar protective profiles, except that at 24 and $96 \mathrm{hr}, 1 \mu \mathrm{M}$ SeNP-Ionic showed slightly higher toxicity than SeNPCovalent. Lower concentrations in SeNPs were nontoxic. The cytotoxic effect of cationic PhG NPs on BT-IMF was similar to BTC. The $\mathrm{LC}_{50}$ values of $\mathrm{Na}$ Sel and the SeNPs for BT-IMF are summarized in Table 1.

In all three cell lines, the $\mathrm{LC}_{50}$ increased significantly in the SeNP treated groups compared to the soluble Na Sel treated cells $(\mathrm{P}<0.05$; Table 1). Data extracted from Table 1 indicated that in RTgutGC the $\mathrm{LC}_{50}$ increased 9.5-fold for SeNP-ionic and 19.2-fold for SeNP-covalent. While in the bovine cell lines the $\mathrm{LC}_{50}$ increased 64.5 and 59.4-fold for SeNP-Ionic and SeNP-Covalent respectively in BTC and 26.9 and 88.43fold for SeNP-Ionic and SeNP-Covalent respectively in BT-IMF.

\section{PhG NPs Did Not Compromise Selenium Bioavailability}

Next, the expression of GPx1 at the transcript level was measured in order to assess whether the reduction in cellular toxicity induced by the SeNPs (SeNP-Ionic or SeNP-Covalent) affected bioavailability of selenium. Using a non-toxic dose $(0.01 \mu \mathrm{M}), \mathrm{GPx} 1$ transcript levels were induced by $\mathrm{Na}$ Sel at $48 \mathrm{~h}$ post treatment, as expected. Interestingly, SeNP-Ionic and SeNP-Covalent induced levels of GPx1 transcript similar to $\mathrm{Na} \mathrm{Sel}$ in all three cell lines tested; RTgutGC (Figure 6A), BTC (Figure 6B) and BT-IMF (Figure 6C) with the exception of BTC treated with SeNP-Covalent which demonstrated higher levels of GPX1 transcript compared to NaSel alone.

GPx activity was then measured at $72 \mathrm{~h}$ post-treatment with Na Sel, SeNP-Ionic or SeNP-Covalent in RTgutGC (Figure 7A), BTC (Figure 7B) and BT-IFM (Figure 7C) cells. Na Sel and SeNP treatments resulted in comparable GPx activity suggesting that the NP delivery system did not impair the bioavailability of selenium.

\section{Discussion}

In the present study, a phytoglycogen nanoparticle ( $\mathrm{PhG}$ $\mathrm{NP}$ ), which is a naturally occurring nanoparticle derived from sweet corn, ${ }^{27}$ was used to deliver inorganic selenium. 

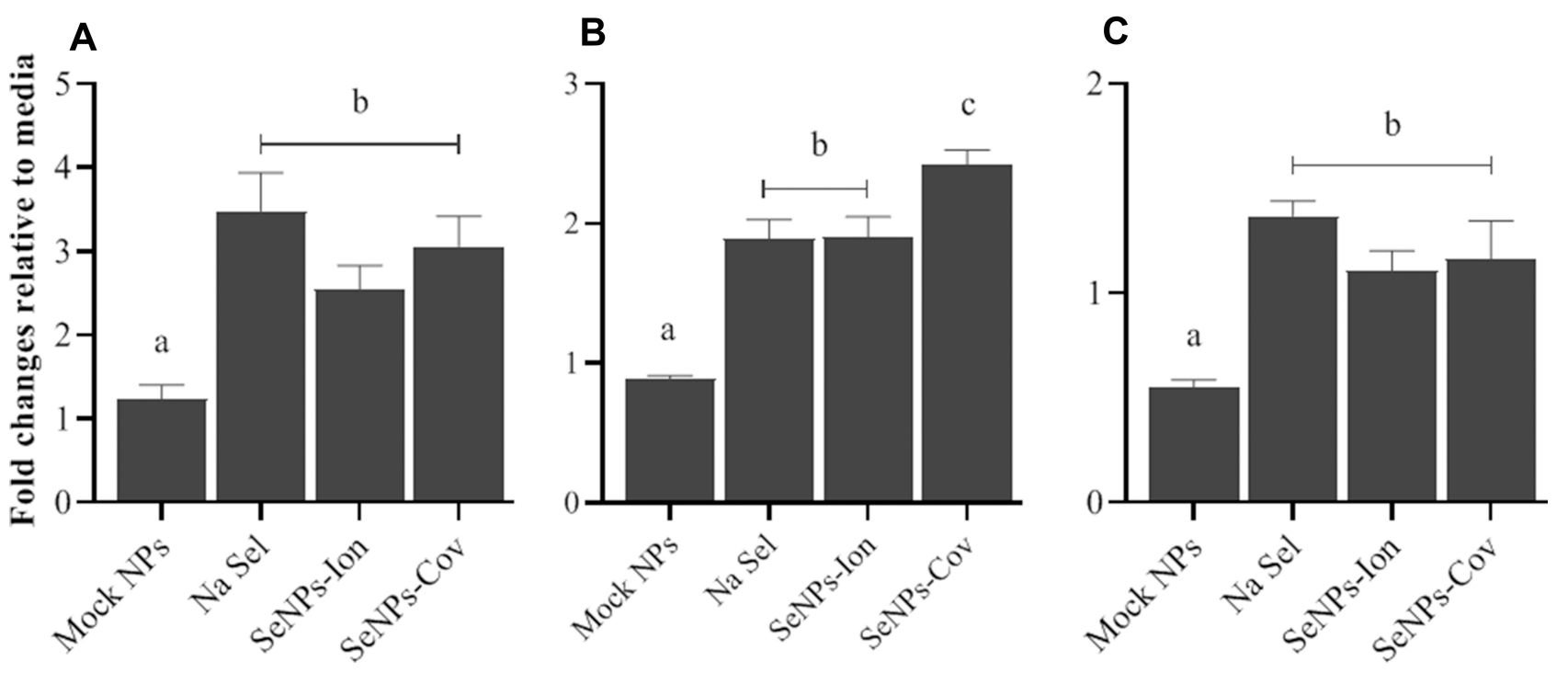

Figure 6 Determining the effects of Na Sel and SeNPs (SeNP-lonic or SeNP-Covalent) on GPxI transcript expression in fish and bovine cells. (A) RTgutGC, (B) BTC and (C) BT-IMF were treated with $0.01 \mu \mathrm{M} \mathrm{Na}$ Sel or SeNPs for $48 \mathrm{hr}$ and the expression of GPxI in treated groups were compared to the control (Media) and was measured by RT-qPCR. Data were given as mean \pm SEM. Different letters show significant differences between treatment groups at $p<0.05$. In the graph, SeNP-lonic is represented as SeNP-lon and SeNP-Covalent as SeNP-Cov.

A

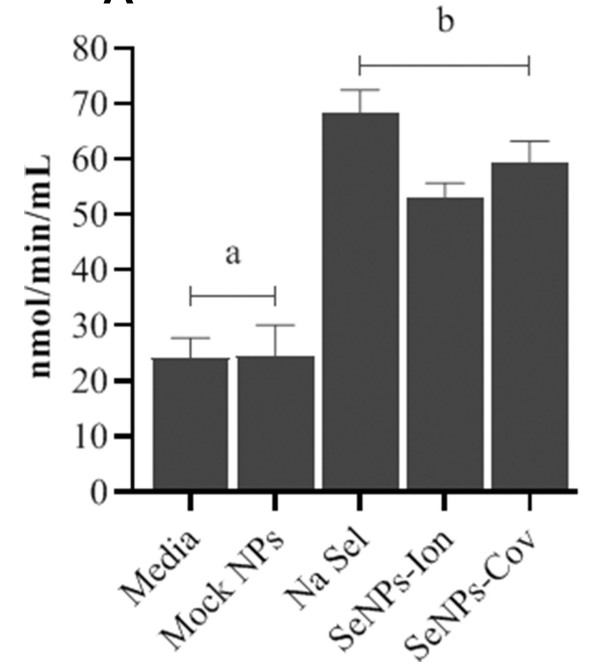

B

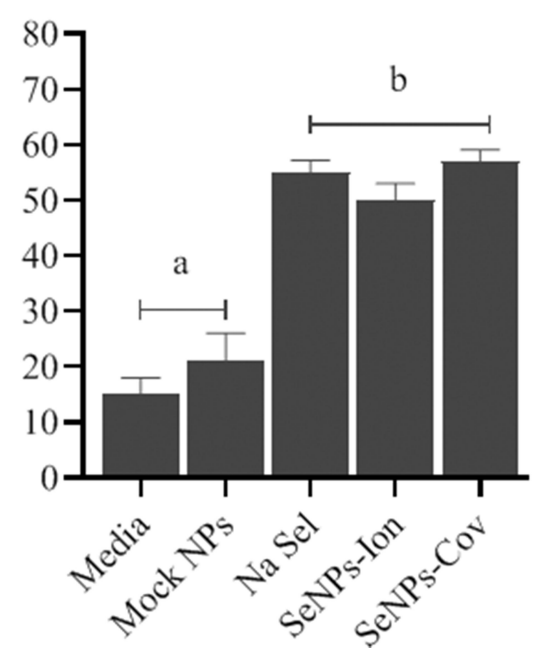

\section{C}

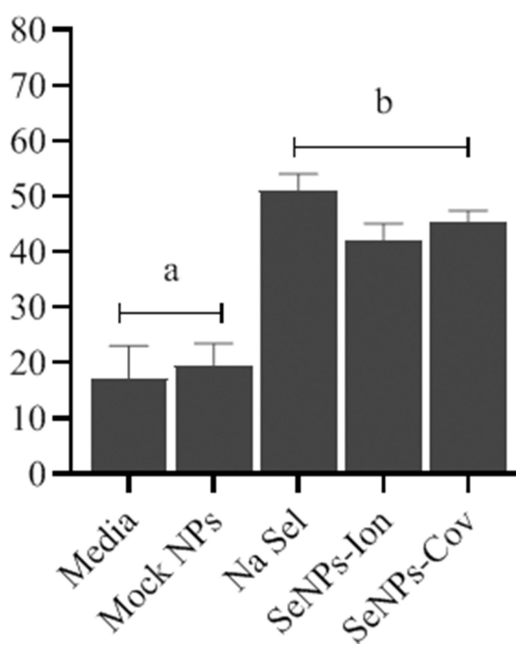

Figure 7 Determining the effects of Na Sel and SeNPs (SeNP-lonic or SeNP-Covalent) on GPx activity in fish and bovine cells. (A) RTgutGC, (B) BTC and (C) BT-IMF cells were treated with $0.01 \mu \mathrm{M}$ Na Sel, SeNP-lonic (SeNPs-lon) or SeNP-Covalent (SeNPs-Cov) for 72 hr. GPx activity in cell lysates was determined with a Glutathione Peroxidase Assay Kit and results were compared to the controls (Media or Mock NPs). Data are expressed as mean \pm SEM. Different letters show significant differences between treatment groups at $\mathrm{p}<0.05$.

Sodium selenite ( $\mathrm{Na} \mathrm{Sel}$ ) was used as a model inorganic compound because of its wide usage as a nutritional supplement due to low cost despite its well-established cytotoxicity. Sodium selenite ( $\mathrm{Na} \mathrm{Sel}$ ) was readily incorporated by electrostatic (ionic) bonding into the PhG NPs with the method described above. However, for the covalent formulation, a selenium dioxide polymer was used as the source of inorganic selenium. SeNP-Ionic or SeNPCovalent demonstrated lower cytotoxicity compared to
$\mathrm{Na}$ Sel alone in both fish and bovine cells. While the toxicity of $\mathrm{Na}$ Sel increased over time, cytotoxicity induced by the SeNPs remained similar over the 4 days of investigation. There are similarities between the present study with SeNPs and nano-selenium studies found in the literature. In a short-term oral toxicity study in mice, nanoselenium made from $\mathrm{Na}$ Sel was found less toxic than $\mathrm{Na}$ $\mathrm{Sel}^{32}$ Indeed, further work in mice demonstrated that nano-selenium $(20-60 \mathrm{~nm})$ prepared as described, ${ }^{32}$ was 
less toxic compared to other forms of selenium. ${ }^{33}$ This correlates with the present study, where the $\mathrm{LC}_{50}$ values from the three cell lines indicate that both SeNP formulations were significantly less toxic compared to $\mathrm{Na}$ Sel. Interestingly, the protective effect of nano-selenium was reported as 7 -fold in mice, ${ }^{32}$ while in the present study using SeNPs, the protection was in all cases higher than that reported in mice; demonstrating between 9.5 and 88.43 fold protection compared to $\mathrm{Na}$ Sel alone.

The mechanisms attributing to a reduction in cytotoxicity in the case of SeNPs compared with soluble $\mathrm{Na}$ Sel is not explored in our study. However, Zhang et al (2001) showed the pro-oxidative effects of nano-selenium was significantly lower than that of soluble $\mathrm{Na} \mathrm{Sel}^{32}$ We speculate that SeNPs compared to $\mathrm{Na}$ Sel might have a balanced antioxidant and pro-oxidant property as opposed to $\mathrm{Na} \mathrm{Sel}$, which always have a pro-oxidant property when used at a higher dose. ${ }^{34}$ It is also unclear how much, if any, Se is released into the extracellular space prior to uptake by cells. The early cytotoxicity observed at $24 \mathrm{~h}$ in RTgutGC and BT-IMF cells treated with SeNP-Ionic compared with SeNP-Covalent (at $10 \mu \mathrm{M}$ for RTgutGC and $1 \mu \mathrm{M}$ for BT-IMF; Figures 3 and 5) suggests that there may be an early release of Se to toxic levels with SeNP-Ionic that does not occur with SeNP-Covalent. Once within the cell, the selenium likely releases from either formulation with hydrolytic enzymatic digestion cleaving the glucose branches of the nanoparticle, releasing soluble selenium intracellularly. Thus, the present nanoparticle delivery system may facilitate a constant release of selenium in the cells over time that may reduce cellular cytotoxicity.

The abilities of selenium species to induce seleniumcontaining enzymes predict their bioavailability in vivo and in vitro. ${ }^{17,35}$ The glutathione peroxidase (GPx) family is an important group of selenium-containing enzymes that detoxify hydroperoxides and lipidic hydroperoxides at the cellular level. ${ }^{1}$ In the current study, the SeNPs enhanced GPx activity to the same level as $\mathrm{Na} \mathrm{Sel}$, when used at a non-toxic concentration $(0.01 \mu \mathrm{M})$. The observed increase in enzyme activity correlated well with a corresponding increase in GPx1 transcript expression. These findings align well with studies with nano-selenium in mice, where GPx and thioredoxin reductase activity was similar or higher to $\mathrm{Na} \mathrm{Sel}$ alone treatments. The mechanism of action for this bioavailability in the SeNPs may be comparable to nano-selenium, both may initiate the synthesis of selenomethionine, which would lead to seleno-cysteine formation and incorporation into GPx catalytic sites. ${ }^{36}$
Alternatively, SeNPs may be inducing GPx transcripts and activity via formation of selenophosphate, an integral part of tRNA selenocysteine. ${ }^{37}$

Previous studies suggest that the size of seleniumbased nanoparticles may be important for seleniuminduced cytotoxicity and bioavailability. With respect to cytotoxicity, in fish intestinal cells smaller nano-selenium (13 $\mathrm{nm}$ in diameter) were found more toxic than intermediate $(42 \mathrm{~nm})$ and larger $(92 \mathrm{~nm})$ nano-selenium and such size-related cytotoxic effects may be cell or tissue dependent. ${ }^{38}$ In mice, however, nano-selenium of $5 \mathrm{~nm}, 20$ $\mathrm{nm}, 36 \mathrm{~nm}, 90 \mathrm{~nm}$ and $200 \mathrm{~nm}$ possessed similar cytotoxicity profiles in vivo and in vitro in hepatocytes, however, their toxicity was by far lower than $\mathrm{Na}$ Sel or organic selenium species. ${ }^{13,32-34}$ With respect to bioavailability, elemental selenium nanostructures $(300 \mathrm{~nm}$ in size) in anaerobic bacteria were not bioavailable. ${ }^{39,40}$ In selenium deficit mice, smaller sized $(36 \mathrm{~nm})$ nano-selenium caused elevated serum and liver selenium compared to larger nano-selenium (90 $\mathrm{nm}$ ); however, differences in plasma GPx activity were not correlated with the size of the NPs. ${ }^{41}$ Additionally, studies in primary cultured intestinal epithelial cells of crucian carp fish showed that intermediate $(42 \mathrm{~nm})$ and large $(92 \mathrm{~nm})$ sized nano-selenium were found more potent enhancers of GPx activity compared to smaller sized nano-selenium $(13 \mathrm{~nm}) .{ }^{38}$ As the size of the SeNPs used in the present study falls between 55 and 68 $\mathrm{nm}$ in diameter, our SeNPs appear to be an ideal size to reduce selenium-induced cytotoxicity while maintaining selenium bioavailability.

Although the uptake and transport efficiency of $\mathrm{Na}$ Sel compared to SeNPs were not investigated in the current study, it has been shown in a human intestinal cell line $(\mathrm{CaCo}-2)$ that both nano-selenium and selenomethionine had higher transport efficiencies compared to $\mathrm{Na} \mathrm{Sel}^{42}$ Interestingly, this difference in transport efficiency did not impair or enhance GPx activity in all the formulations tested. ${ }^{42}$ Moreover, the nanoparticle delivery system may facilitate a constant lowlevel release of selenium over time compared to a single exposure to $\mathrm{Na}$ Sel delivered in its soluble form.

\section{Conclusion}

Inorganic selenium delivered by PhG NPs demonstrated reduced cytotoxicity but maintained its bioavailability compared to $\mathrm{Na}$ Sel alone in both rainbow trout and bovine cell cultures. The present study suggests that SeNPs are likely a safer alternative to $\mathrm{Na} \mathrm{Sel}$, where increased doses of selenium delivered by the nanoparticle 
formulation can have reduced cytotoxicity but maintained reduction in oxidative stress, to ultimately increase the productivity of stress-ridden fish and livestock.

\section{Acknowledgments}

This work was supported by the Alberta-Ontario Innovation Program and an NSERC discovery grant, both awarded to SDO. We would also like to thank Niels Bols (University of Waterloo) and Lucy Lee (University of the Fraser Valley) for providing the cell lines for this study, and Glysantis Inc. for providing the cationic phytoglycogen nanoparticles.

\section{Disclosure}

The nanoparticles used in this study were supplied by Glysantis, free of charge. Jondavid deJong reports that they were associated with Glysantis Inc in an unpaid role, and was involved in experimental execution but not nanoparticle development and production. Emily Moore, an employee of Glysantis Inc., produced the selenium-conjugated nanoparticles but was not involved in experimental design or execution, and reports a patent pending: 55727555-16USPR. Stephanie DeWitte-Orr and Tamiru N Alkie report a patent pending: Compounds and compositions of selenium with reduced toxicity; and worked with Glysantis Inc, an industrial partner, on this project. The work was funded by a grant received through a competitive grant review process by federal and provincial funding agencies. Glysantis provided the nanoparticle as an in-kind contribution to the project. The money to fund the project came from the grant. The authors report no other potential conflicts of interest for this work.

\section{References}

1. Rayman MP. The importance of selenium to human health. Lancet. 2000;356:233-241.

2. Epp O, Ladenstein R, Wendel A. The refined structure of the selenoenzyme glutathione peroxidase at $0.2-\mathrm{nm}$ resolution. Eur J Biochem. 1983;133:51-69. doi:10.1111/j.1432-1033.1983.tb07429.x

3. Spallholz JE. On the nature of selenium toxicity and carcinostatic activity. Free Radic Biol Med. 1994;17(1):45-64. doi:10.1016/08915849(94)90007-8

4. Burk RF, Norsworthy BK, Hill KE, et al. Effects of chemical form of selenium on plasma biomarkers in a high-dose human supplementation trial. Cancer Epidemiol Biomarkers Prev. 2006;15:804-810. doi:10.11 58/1055-9965.EPI-05-0950

5. Tiwary AK, Stegelmeier BL, Panter KE, et al. Comparative toxicosis of sodium selenite and selenomethionine in lambs. $J$ Vet Diagn Invest. 2006;18(1):61-70. doi:10.1177/104063870601800108
6. Berntssen MHG, Sundal TK, Olsvik PA, et al. Sensitivity and toxic mode of action of dietary organic and inorganic selenium in atlantic salmon (Salmo salar). Aquat Toxicol. 2017;192:116-126. doi:10.10 16/j.aquatox.2017.09.014

7. Clark RF, Strukle E, Williams SR, et al. Selenium poisoning from a nutritional supplement. JAMA. 1996;275:1087-1088. doi:10.1001/ jama.1996.03530380029025

8. Thomson CD. Assessment of requirements for selenium and adequacy of selenium status: a review. Eur J Clin Nutr. 2004;58:391-402.

9. Ip C. Lessons from basic research in selenium and cancer prevention. J Nutr. 1998;128:1845-1854.

10. Tanaka T, Kohno H, Murakami M, et al. Suppressing effects of dietary supplementation of the organoselenium 1,4-phenylenebis (methylene)selenocyanate and the citrus antioxidant auraptene on lung metastasis of melanoma cells in mice. Cancer Res. 2000; 60:3713-3716.

11. Zoidis E, Seremelis I, Kontopoulos N, et al. Selenium-dependent antioxidant enzymes: actions and properties of selenoproteins. Antioxidants. 2018;7(5):66. doi:10.3390/antiox7050066

12. Rayman MP. Food-chain selenium and human health: emphasis on intake. Br J Nutr. 2008;100(2):254-268. doi:10.1017/S0007114508939830

13. Zhang J, Wang H, Bao Y, et al. Nano red elemental selenium has no size effect in the induction of seleno-enzymes in both cultured cells and mice. Life Sci. 2004;75(2):237-244. doi:10.1016/j.lfs.2004.02.004

14. Shin Y, Blackwood JM, Bae IT, et al. Synthesis and stabilization of selenium nanoparticles on cellulose nanocrystal. Mater Lett. 2007;61 (21):4297-4300. doi:10.1016/j.matlet.2007.01.091

15. Dwivedi C, Shah CP, Singh K, et al. An organic acid-induced synthesis and characterization of selenium nanoparticles. J Nanotechnol. 2011;2011:1-6. doi:10.1155/2011/651971

16. Zhou X, Wang Y, Gu Q, et al. Effects of different dietary selenium sources (selenium nanoparticle and selenomethionine) on growth performance, muscle composition and glutathione peroxidase enzyme activity of crucian carp (Carassius auratus gibelio). Aquaculture. 2009;291(1-2):78-81. doi:10.1016/j.aquaculture.2009.03.007

17. Fairweather-Tait SJ, Collings R, Hurst R. Selenium bioavailability: current knowledge and future research. Am J Clin Nutr. 2010;91:1484S-1491S. doi:10.3945/ajen.2010.28674J

18. Constantinescu-Aruxandei D, Frîncu RM, Capră L, et al. Selenium analysis and speciation in dietary supplements based on next-generation selenium ingredients. Nutrients. 2018;10(10):1466. doi:10.3390/ nu10101466

19. Gao Z, Zhang C, Tian C, et al. Characterization, antioxidation, antiinflammation and renoprotection effects of selenized mycelia polysaccharides from Oudemansiella radicata. Carbohydr Polym. 2018;181:1224-1234. doi:10.1016/j.carbpol.2017.12.007

20. Ashouri S, Keyvanshokooh S, Salati AP, et al. Effects of different levels of dietary selenium nanoparticles on growth performance, muscle composition, blood biochemical profiles and antioxidant status of common carp (Cyprinus carpio). Aquaculture. 2015;446:2529. doi:10.1016/j.aquaculture.2015.04.021

21. Naderi M, Keyvanshokooh S, Salati AP, et al. Combined or individual effects of dietary vitamin $\mathrm{E}$ and selenium nanoparticles on humoral immune status and serum parameters of rainbow trout (Oncorhynchus mykiss) under high stocking density. Aquaculture. 2017;474:40-47. doi:10.1016/j.aquaculture.2017.03.036

22. Saffari S, Keyvanshokooh S, Zakeri M, et al. Effects of different dietary selenium sources (sodium selenite, selenomethionine and nanoselenium) on growth performance, muscle composition, blood enzymes and antioxidant status of common carp (Cyprinus carpio). Aquac Nutr. 2017;23(3):611-617. doi:10.1111/anu.12428

23. Dawood MAO, Koshio S, Zaineldin AI, et al. An evaluation of dietary selenium nanoparticles for red sea bream (Pagrus major) aquaculture: growth, tissue bioaccumulation, and antioxidative responses. Environ Sci Pollut Res. 2019;26:30876-30884. doi:10.10 07/s11356-019-06223-6 
24. Eszenyi P, Sztrik A, Babka B, et al. Elemental, nano-sized (100-500 $\mathrm{nm}$ ) selenium production by probiotic lactic acid bacteria. Int J Biosci Biochem Bioinforma. 2010;1:148-152.

25. Luo Y, Zhang B, Cheng W-H, et al. Preparation, characterization and evaluation of selenite-loaded chitosan/TPP nanoparticles with or without zein coating. Carbohydr Polym. 2010;82(3):942-951. doi:10. 1016/j.carbpol.2010.06.029

26. Zhang S, Luo Y, Zeng H, et al. Encapsulation of selenium in chitosan nanoparticles improves selenium availability and protects cells from selenium-induced DNA damage response. J Nutr Biochem. 2011;22 (12):1137-1142. doi:10.3390/ijms20225606

27. Nickels JD, Atkinson J, Papp-Szabo E, et al. Structure and hydration of highly-branched, monodisperse phytoglycogen nanoparticles. Biomacromolecules. 2016;17(3):735-743. doi:10.1021/acs.biomac. 5 b01393

28. Wang W, Meng Q, Li Q, et al. Chitosan derivatives and their application in biomedicine. Int J Mol Sci. 2020;21(2):487. doi:10.3390/ ijms 21020487

29. Alkie TN, de Jong J, Jenik K, et al. Enhancing innate antiviral immune responses in rainbow trout by double stranded RNA delivered with cationic phytoglycogen nanoparticles. Sci Rep. 2019;9 (1):13619. doi:10.1038/s41598-019-49931-2

30. Kawano A, Haiduk C, Schirmer K, et al. Development of a rainbow trout intestinal epithelial cell line and its response to lipopolysaccharide. Aquac Nutr. 2011;17(2):241-252. doi:10.1111/j.1365-2095.2010.00757.x

31. Fadeeva VP, Panin DO, Nikulicheva ON, et al. Extraction-spectrophotometric determination of selenium in organoselenium compounds using aromatic o-diamines. J Anal Chem. 2014;69:432-437.

32. Zhang JS, Gao XY, Zhang LD, et al. Biological effects of a nano red elemental selenium. Biofactors. 2001;15(1):27-38. doi:10.1002/ biof.5520150103

33. Wang H, Zhang J, Yu H. Elemental selenium at nano size possesses lower toxicity without compromising the fundamental effect on selenoenzymes: comparison with selenomethionine in mice. Free Radic Biol Med. 2007;42:1524-1533. doi:10.1016/j.freeradbiomed.2007.02.013
34. Zhang J, Wang H, Yan X, et al. Comparison of short-term toxicity between Nano-Se and selenite in mice. Life Sci. 2005;76(10):10991109. doi:10.1016/j.1fs.2004.08.015

35. Zeng H, Jackson MI, Cheng W-H, et al. Chemical form of selenium affects its uptake, transport, and glutathione peroxidase activity in the human intestinal Caco-2 cell model. Biol Trace Elem Res. 2011;143 (2):1209-1218. doi:10.1007/s12011-010-8935-3

36. Forstrom JW, Zakowski JJ, Tappel AL. Identification of the catalytic site of rat liver glutathione peroxidase as selenocysteine. Biochemistry. 1978;17(13):2639-2644. doi:10.1021/bi00606a028

37. Mizutani T, Goto C, Totsuka T. Mammalian Selenocysteine tRNA, its enzymes and selenophosphate. J Heal Sci. 2000;46:399-404. doi:10.1248/jhs.46.399

38. Wang Y, Yan X, Fu L. Effect of selenium nanoparticles with different sizes in primary cultured intestinal epithelial cells of crucian carp, Carassius auratus gibelio. Int J Nanomedicine. 2013;8:4007-4013. doi:10.2147/IJN.S43691

39. Oremland RS, Herbel MJ, Blum JS, et al. Structural and spectral features of selenium nanospheres produced by Se-respiring bacteria. Appl Environ Microbiol. 2004;70(1):52-60. doi:10.1128/AEM.70.1. 52-60.2004

40. Dowdle PR, Oremland RS. Microbial oxidation of elemental selenium in soil slurries and bacterial cultures. Environ Sci Technol. 1998;32:3749-3755.

41. Peng D, Zhang J, Liu Q, et al. Size effect of elemental selenium nanoparticles (Nano-Se) at supranutritional levels on selenium accumulation and glutathione $\mathrm{S}$-transferase activity. J Heal Sci. 2007;101:1457-1463.

42. Wang Y, Fu L. Forms of selenium affect its transport, Uptake and glutathione peroxidase activity in the caco-2 cell model. Biol Trace Elem Res. 2012;149(1):110-116. doi:10.1007/s12011-012-9395-8
International Journal of Nanomedicine

\section{Publish your work in this journal}

The International Journal of Nanomedicine is an international, peerreviewed journal focusing on the application of nanotechnology in diagnostics, therapeutics, and drug delivery systems throughout the biomedical field. This journal is indexed on PubMed Central, MedLine, CAS, SciSearch ${ }^{\mathbb{2}}$, Current Contents ${ }^{\mathbb{R}} /$ Clinical Medicine, $^{2}$
Journal Citation Reports/Science Edition, EMBase, Scopus and the Elsevier Bibliographic databases. The manuscript management system is completely online and includes a very quick and fair peer-review system, which is all easy to use. Visit http://www.dovepress.com/ testimonials.php to read real quotes from published authors. 